\title{
Post Discharge Short Term Mortality in Hospitalized Patients with Community-Acquired Pneumonia
}

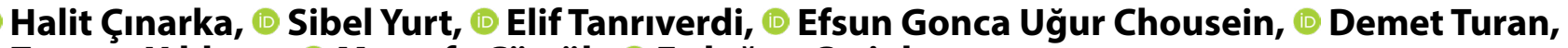 \\ Zeynep Yıldırım, (1) Mustafa Çörtük, Erdoğan Çetinkaya \\ Department of Chest Diseases, University of Health Sciences Turkey, Yedikule Chest Disease Training and Research Hospital, Istanbul, Turkey
}

\begin{abstract}
Introduction: Community-acquired pneumonia (CAP) is one of the most important causes of morbidity and mortality in developed countries, especially in the elderly and adults. Thus, the relationship between CAP and short and long-term mortality in patients is critical. A better understanding of CAP related mortality factors can enable us to make inferences for patient care. In this study, we aimed to determine the short-term (1 month) mortality rate for CAP after hospitalization and to find the risk factors associated with mortality.

Methods: Hospitalized patients with CAP were classified into two groups as follows: patients who died within 1-month after hospital discharge and patients who survived in the same period. All patients' data recorded in a computer-assisted protocol. Data were collected on demographic characteristics, comorbidities, causative organisms, laboratory findings, and survival situations.

Results: The findings showed that 489 non-immunosuppressed adults with CAP were hospitalized. 11.4\% patients died 1-month after the hospitalization. The frequency of male sex and current smokers were similar between the groups. However, patients who died in 1-month after hospital discharge were older. Regarding comorbidities, patients who died within 1-month after hospital discharge more often had chronic renal disease; other comorbidities were more seen in alive patients. Patients who died within 1-month after hospital discharge more often had higher WBC, Neutrophil, Procalcitonin, BUN, AST, $\mathrm{PaCO}_{2}$ value, and lower lymphocyte, $\mathrm{Hct}, \mathrm{Hb}$, protein, albumin value than who survived. Length of hospital stay was longer in survived patients than died patients.

Discussion and Conclusion: The findings obtained in this study suggest that mortality of in-patients with CAP is remarkably high. Although we could not show any significant independent risk factor for mortality, we can say that some laboratory parameters and some comorbid conditions may affect the mortality rate. Our findings may help to understand the relationship between CAP and mortality, and designing optimal management of comorbidities in this population after discharge. Keywords: Hospital-acquired pnemonia; post discharge mortality; markers.
\end{abstract}

C ommunity-acquired pneumonia (CAP) is one of the major causes of morbidity and mortality in adults in developed countries, especially in the elderly ${ }^{[1]}$. Also, it is a common reason for hospitalization approximately 20$25 \%$ of CAP patients require inpatient treatment. Severe
CAP, defined as admission to the intensive care unit (ICU), develops in approximately $10-20 \%$ of inpatients ${ }^{[2]}$. Mortality rates reported as $<1 \%$ to $>40 \%$ according to treatment setting, disease severity, age and comorbidities ${ }^{[3]}$. Hospital mortality rate for CAP patients is approximately $13 \%{ }^{[4]}$.

Correspondence (İletişim): Halit Çınarka, M.D. Saglik Bilimleri Universitesi Yedikule Gogus Hastaliklari Egitim ve Arastirma Hastanesi, Istanbul, Turkey Phone (Telefon): +905325633812 E-mail (E-posta): halitcinarka@hotmail.com 
Moreover, it has been shown that hospitalization for CAP is associated with high long-term mortality compared with other major medical conditions. The frequency of longterm mortality reported in these studies ranged from $11 \%$ to $53 \%{ }^{[5,6]}$. Therefore, it has been stated that CAP should be recognized as a medical emergency due to its acute lifethreatening condition ${ }^{[7]}$. In our country, lower respiratory tract infections are ranked as the 5th cause of death with a rate of $4.2 \%{ }^{[8]}$. In addition, mortality rate in CAP patients hospitalized in our country has been reported as $9.7 \%$, mortality-related factors have been reported as advanced age and presence of comorbidity ${ }^{[9]}$. There is an important interest in determining the relationship between CAP and short- and long-term mortality in surviving patients. A better understanding of the factors associated with this complication can enable us to make inferences for patient care. Therefore, this is a crucial issue that requires comprehensive evaluation. We aimed to determine the short term (1 month) mortality rate after hospitalization for CAP, and to find out the risk factors related with mortality in this study.

\section{Materials and Methods}

This retrospective study was carried out in a Training and Research Hospital for adults. All adult patients $>17$ years of age with CAP who were admitted to the hospital from 1 January 2009 to 31 December 2017 were recruited. CAP was identified using ICD-10 codes (International Classification of Diseases, $10^{\text {th }}$ Revision). The case definition for hospitalized CAP was hospitalization and either one of the main discharge diagnoses of pneumonia. Mortality of CAP was defined as death for any reason occurring within 30 days of the CAP case definition.

Patients with neutropenia, immunoglobulin deficiencies, HIV infection, transplantation or splenectomy, those who were receiving immunosuppressant and/or corticosteroid therapy were not included in this study. Hospitalized patients with CAP were classified into two groups: patients who died within 1-month after hospital discharge and patients who survived in the same period.

All patients' data recorded in a computer-assisted protocol. Data were collected on demographic characteristics, comorbidities, causative organisms, laboratory findings, and survival situation.

Mortality data mostly depends on regular examinations recorded in hospital software data. Additionally, searches were conducted from the national death reporting system (https://obs.saglik.gov.tr/Account/Login). This study was approved by applying to the Istanbul Training and Re- search Hospital Ethics Committee (Ethics committee number: 2142, date:10.01.2020).

The statistical analysis was performed with version 22.0 of the SPSS software package. P-values less than 0.05 were considered statistically significant. All reported p-values were 2-tailed. Significant differences between groups were detected using the chi-square test for categorical variables. For continuous variables, we used the Student's t-test or Mann Whitney $U$ test, depending on the results of the Kolmogorov Smirnov normality test. The logistic regression model of factors potentially associated with 1-month mortality included all the significant variables in the multivariate analysis $(p<.05)$ with clinical importance.

\section{Results}

During the study period, 489 non-immunosuppressed adults with CAP were hospitalized. Fifty-six (11.4\%) patients died 1-month after hospitalization. The demographic features at hospital admission of patients who survived and died in 1-month after hospital discharge are compared in Table 1. The frequency of male sex and current/former smokers were similar between the groups. However, patients who died in 1-month after hospital discharge were older ( $p>0.05$ ). Regarding comorbidities, patients who died within 1-month after hospital discharge more often had chronic renal disease. Other comorbidities were more seen in alive patients.

The laboratory findings at hospital admission of patients who survived and died within 1-month of leaving hospital are compared in Table 2. Patients who died within 1-month after hospital discharge more often had higher WBC, Neutrophil, Procalcitonin, BUN, AST, $\mathrm{PaCO}_{2}$ value, and lower lymphocyte, $\mathrm{Hct}, \mathrm{Hb}$, protein, albumin value than who survived. Other laboratory parameters showed no significant difference between groups. Length of hospital stay was longer in survived patients than patients who died

Table 1. Demographic characteristics at hospital admission of patients with all CAP patients (survived and died)

\begin{tabular}{lcc}
\hline Characteristic & Alive $(\mathbf{n}=\mathbf{4 3 3})$ & Died $(\mathbf{n}=\mathbf{5 6})$ \\
\hline Age (years, mean) & $62.60 \pm 16.20$ & $65.39 \pm 14.02$ \\
Male sex (n,\%) & $319(73.67)$ & $41(73.21)$ \\
Current/former smoker $(\mathrm{n}, \%)$ & $236(54.50)$ & $26(46.42)$ \\
Comorbidities & & \\
$\quad$ Diabetes mellitus & $75(17.32)$ & $5(8.92)$ \\
$\quad$ Chronic respiratory disease & $191(44.11)$ & $21(37.5)$ \\
Cardiac disease & $182(42.03)$ & $20(35.71)$ \\
$\quad$ Chronic renal disease & $18(4.15)$ & $5(8.92)$ \\
\hline
\end{tabular}


(9.95 \pm 6.46 day vs. $8.17 \pm 6.31$ day, $p=0.019)$. We were not able to determine risk factors independently associated with 1-month mortality. The results of the regression analysis for factors that are potentially associated with 1-month mortality after hospital discharge in patients with CAP are summarized in Table 3.

Table 2. Laboratory findings at hospital admission of patients with all CAP patients (survived and died)

\begin{tabular}{|c|c|c|c|}
\hline Characteristic & Alive $(n=433)$ & Died $(n=56)$ & $\mathbf{p}$ \\
\hline \multicolumn{4}{|l|}{ Whole blood count } \\
\hline WBC $\left(10^{3} / \mu \mathrm{L}\right)$ & $12.20 \pm 7.21$ & $15.79 \pm 11.85$ & 0.000 \\
\hline Neutrophil $\left(10^{3} / \mu \mathrm{L}\right)$ & $9.83 \pm 6.70$ & $12.02 \pm 6.11$ & 0.001 \\
\hline Lymphocyte $\left(10^{3} / \mu \mathrm{L}\right)$ & $1.38 \pm 2.50$ & $0.91 \pm 0.98$ & 0.000 \\
\hline Platelet $\left(10^{3} / \mu \mathrm{L}\right)$ & $293.26 \pm 127.58$ & $272.25 \pm 137.15$ & $>0.05$ \\
\hline Hct (\%) & $37.47 \pm 6.67$ & $35.44 \pm 6.48$ & 0.047 \\
\hline $\mathrm{Hb}(\mathrm{g} / \mathrm{dL})$ & $12.09 \pm 2.17$ & $11.37 \pm 2.18$ & 0.02 \\
\hline $\mathrm{CRP}(\mathrm{mg} / \mathrm{L})$ & $145 \pm 10.90$ & $170.23 \pm 10.14$ & 0.053 \\
\hline $\mathrm{ESR}(\mathrm{mm} / \mathrm{h})$ & $70.10 \pm 34.15$ & $66.73 \pm 36.59$ & $>0.05$ \\
\hline Procalcitonin (mg/L) & $0.21 \pm 0.23$ & $0.29 \pm 0.23$ & 0.013 \\
\hline \multicolumn{4}{|l|}{ Biochemistry } \\
\hline Glucose (mg/dL) & $151.92 \pm 88.24$ & $143.37 \pm 65.30$ & $>0.05$ \\
\hline $\mathrm{Na}(\mathrm{mEq} / \mathrm{L})$ & $137.60 \pm 21.01$ & $135.87 \pm 5.09$ & $>0.05$ \\
\hline BUN (mg/dL) & $45.51 \pm 24.41$ & $67.17 \pm 39.13$ & 0.000 \\
\hline Protein (g/dL) & $6.60 \pm 0.80$ & $6.17 \pm 0.92$ & 0.001 \\
\hline Albumin (g/dL) & $3.27 \pm 0.54$ & $2.88 \pm 0.53$ & 0.000 \\
\hline ALT (U/L) & $30.91 \pm 43.47$ & $46.01 \pm 69.38$ & $>0.05$ \\
\hline AST (U/L) & $34.08 \pm 63.41$ & $74.65 \pm 178.69$ & 0.031 \\
\hline \multicolumn{4}{|l|}{ Arterial Blood Gas } \\
\hline $\mathrm{pH}$ & $7.432 .35 \pm 0.070$ & $7.418 .32 \pm 0.125$ & $>0.05$ \\
\hline $\mathrm{PaO}_{2}(\mathrm{mmHg})$ & $71.25 \pm 29.97$ & $84.02 \pm 54.80$ & $>0.05$ \\
\hline $\mathrm{PaCO}_{2}(\mathrm{mmHg})$ & $42.32 \pm 13.57$ & $48.54 \pm 19.82$ & 0.035 \\
\hline
\end{tabular}

Table 3. Factors associated with 1-month mortality after discharge for CAP patients

\begin{tabular}{lccc}
\hline Characteristic & Odds ratio & 95\% Confidence interval & p \\
\hline CRP & 3.07 & $0.00-0.00$ & 0.99 \\
Glucose & 2.13 & $0.062-73.07$ & 0.67 \\
Neutrophil & 0.00 & $0.00-0.00$ & 1.00 \\
Lymphocyte & 0.69 & $0.19-2.50$ & 0.57 \\
WBC & 1.05 & $0.20-5.55$ & 0.95 \\
$\mathrm{Hct}$ & 1.85 & $0.23-15.04$ & 0.56 \\
$\mathrm{Hb}$ & 1.43 & $0.18-11.09$ & 0.73 \\
PaCO & 3.15 & $0.90-10.99$ & 0.07 \\
$\mathrm{BUN}$ & 2.62 & $0.74-9.25$ & 0.13 \\
Procalcitonin & 1.71 & $0.43-6.77$ & 0.44 \\
Protein & 1.18 & $0.28-4.98$ & 0.82 \\
Albumin & 0.00 & $0.00-0.00$ & 1.00 \\
AST & 2.69 & $0.68-10.53$ & 0.15 \\
\hline
\end{tabular}

\section{Discussion}

In this retrospective study of a large cohort of hospitalized patients with CAP, we found that $11.45 \%$ of patients died within the first month after hospital discharge. Although we observed that some laboratory parameters showed a significant difference in survived patients, we were not able to determine risk factors independently associated with 1-month mortality after hospital discharge.

There are some reports documenting the mortality rate in CAP patients. In Adamuz et al.'s study, they prospectively analysed CAP patients who were hospitalized and they documented that 241 (15.2\%) patients died during a 1-year follow-up after hospital admission. Of these, 93 (7.2\%) died within 1-year of leaving the hospital. Another finding of this study was, after the first months of hospital discharge, the cases of mortality from infectious diseases decreased progressively, while deaths from acute cardiovascular causes showed stability throughout the follow-up ${ }^{[10]}$. Other previous reports found a frequency of long-term mortality from $11 \%$ to $53 \%$ in CAP patients ${ }^{[5,6,11]}$. However, these studies evaluated longer-term mortality during 1-7 years of follow-up, and some of them included in-hospital mortality. Another study reported in-hospital mortality rate of CAP patients as $17.2 \%$. They explained the cause of this mortality rate by including patients with haematological malignancies and immunosuppression in their population, who are known to have a high incidence of CAP and carry a worse prognosis ${ }^{[12]}$. One of the important risk factors for mortality in hospitalized CAP patients is the presence of comorbidities. We found that non-survived patients had more often chronic renal disease than survived patients. Another study documented that COPD, diabetes mellitus, cancer, dementia, rehospitalization within 30 days of hospital discharge and nursing home residence were independent predictors of 1-year mortality after hospital discharge ${ }^{[10]}$. Mortensen et al. reported that rehospitalization for another episode of pneumonia, cardiovascular and cerebrovascular disease and exacerbation of COPD was frequent after initial hospitalization for pneumonia ${ }^{[5]}$. Moreover, cancer, high glucose level, dementia and nursing home residence were also have been identified as independent predictors of long-term mortality by others ${ }^{[11,13,14]}$. Comorbidities are not only important for mortality.

Kolditz et al. ${ }^{[12]}$ evaluated that chronic comorbidities (with the highest ORs associated with respiratory, neurologic and immunosuppressive disease) are independently associated with a higher incidence of CAP. Therefore, it can be said that these patients should be supported by the 
current recommendations for targeting preventive measures. Moreover, this underscores the importance of careful evaluation of chronic comorbidities in every patient with CAP. Because the risk of organ dysfunction due to comorbidity decompensation and prognostic impact of severe, advanced comorbidities may result in possible treatment restrictions. On the other hand, it is showed that chronic respiratory disease can have a protective role. Dusemund et al. ${ }^{[15]}$ found fewer disease-related complications of CAP in COPD and asthma patients compared with their controls. In-hospital mortality was lower in the COPD and much more pronounced asthma cohorts. A possible mechanism of this finding can be earlier symptom onset of milder CAP in patients with lung disease with subsequent earlier treatment. We also determined that survived patients had more often respiratory disease than non-survived patients. In contrast, a recent meta-analysis found inconsistent effects of COPD on CAP prognosis ${ }^{[16]}$. Previous studies documented that age could be another risk factor for mortality in this patient population ${ }^{[6,13,17]}$. However, in Adamuz et al.'s ${ }^{[10]}$ study, age was not independently associated with 1-year mortality in the adjusted model. In our study, although non-survived patients were older than alive patients, it could not reach statistical significance. Similarly, some researchers have documented that, in an elderly population, age per se is not an independent predictor of hospital mortality in CAP patients ${ }^{[14]}$. Sex, which is a part of the PSI score, is also accepted as a strong independent risk factor for worse CAP prognosis ${ }^{[19,20]}$. However, Arnold et al. ${ }^{[20]}$ reported that females have worse outcomes for CAP than males. In our study, we were not able to show that sex is an independent risk factor, but we saw that sex is not different in survived and non-survived patients.

The limitations of this study are its retrospective design, conducted in a single-center, and obtaining information about 1-month mortality from the hospital database. We had no data on causes of death. We were not able to provide data on pneumonia severity. Comorbidities were retrieved from ICD-10 coding and not validated by clinical data. Additionally, there are no data on the use of immunosuppressive medications.

\section{Conclusion}

This study indicates that the mortality of in-patients with CAP is remarkably high. Although we could not show any significant independent risk factor for mortality, we can say that some laboratory parameters and some comorbid conditions can affect the mortality rate. Our findings may help to understand the relationship between CAP and mortal- ity, and designing optimal management of comorbidities in this population after discharge.

Ethics Committee Approval: Health Sciences University Istanbul Training and Research Hospital Clinical Research Ethics Committee (2011-KAEK-50).

Peer-review: Externally peer-reviewed.

Authorship Contributions: Concept: H.Ç., S.Y.; Design: H.Ç.; Data Collection or Processing: E.T., E.U.G.C.; Analysis or Interpretation: D.T., Z.Y., M.Ç.; Literature Search: H.Ç., E.Ç.; Writing: H.Ç.

Conflict of Interest: None declared.

Financial Disclosure: The authors declared that this study received no financial support.

\section{References}

1. Torres A, Peetermans WE, Viegi G, Blasi F. Risk factors for community-acquired pneumonia in adults in Europe: a literature review. Thorax 2013;68:1057-65. [CrossRef]

2. Jain S, Self WH, Wunderink RG, Fakhran S, Balk R, Bramley AM, et al; CDC EPIC Study Team. Community-Acquired Pneumonia Requiring Hospitalization among U.S. Adults. N Engl J Med 2015;373:415-27. [CrossRef]

3. Welte T, Torres A, Nathwani D. Clinical and economic burden of community-acquired pneumonia among adults in Europe. Thorax 2012;67:71-9. [CrossRef]

4. Ewig S, Birkner N, Strauss R, Schaefer E, Pauletzki J, Bischoff $\mathrm{H}$, et al. New perspectives on community-acquired pneumonia in 388406 patients. Results from a nationwide mandatory performance measurement programme in healthcare quality. Thorax 2009;64:1062-9. [CrossRef]

5. Mortensen EM, Metersky ML. Long-term mortality after pneumonia. Semin Respir Crit Care Med 2012;33:319-24. [CrossRef]

6. Johnstone J, Eurich DT, Majumdar SR, Jin Y, Marrie TJ. Longterm morbidity and mortality after hospitalization with community-acquired pneumonia: a population-based cohort study. Medicine (Baltimore) 2008;87:329-34. [CrossRef]

7. Ewig S, Torres A. Community-acquired pneumonia as an emergency: time for an aggressive intervention to lower mortality. Eur Respir J 2011;38:253-60. [CrossRef]

8. T.C. Sağlık Bakanlığı, Refik Saydam Hıfzıssıhha Merkezi Başkanlığı Hıfzıssıhha Mektebi Müdürlüğü, Başkent Üniversitesi Ulusal Hastalık Yükü ve Maliyeti Etkinlik Projesi, 2004 (www. toraks.org.tr).

9. Sever F, Kömüs N, Esen N, Gündüz AT, MA Öktem, Çımrın AH. Etiology and Epidemiology of Community-Acquired Pneumonia in Turkey. Turk Thorac J 2013;14:5-10. [CrossRef]

10. Adamuz J, Viasus $D$, Jiménez-Martínez $E$, Isla $P$, Garcia-Vidal $C$, Dorca J, et al. Incidence, timing and risk factors associated with 1-year mortality after hospitalization for community-acquired pneumonia. J Infect 2014;68:534-41. [CrossRef]

11. Mortensen EM, Kapoor WN, Chang CC, Fine MJ. Assessment of mortality after long-term follow-up of patients with community-acquired pneumonia. Clin Infect Dis 2003;37:1617-24. 
12. Kolditz M, Tesch F, Mocke L, Höffken G, Ewig S, Schmitt J. Burden and risk factors of ambulatory or hospitalized CAP: A population based cohort study. Respir Med 2016;121:32-8.

13. Waterer GW, Kessler LA, Wunderink RG. Medium-term survival after hospitalization with community-acquired pneumonia. Am J Respir Crit Care Med 2004;169:910-4. [CrossRef]

14. Bruns AH, Oosterheert JJ, Cucciolillo MC, El Moussaoui R, Groenwold RH, Prins JM, et al. Cause-specific long-term mortality rates in patients recovered from community-acquired pneumonia as compared with the general Dutch population. Clin Microbiol Infect 2011;17:763-8. [CrossRef]

15. Dusemund F, Chronis J, Baty F, Albrich WC, Brutsche MH. The outcome of community-acquired pneumonia in patients with chronic lung disease: a case-control study. Swiss Med Wkly 2014;144:w14013. [CrossRef]

16. Loke YK, Kwok CS, Wong JM, Sankaran P, Myint PK. Chronic obstructive pulmonary disease and mortality from pneumonia: meta-analysis. Int J Clin Pract 2013;67:477-87. [CrossRef]
17. Cecere LM, Rubenfeld GD, Park DR, Root RK, Goss CH. Long-term survival after hospitalization for community-acquired and healthcare-associated pneumonia. Respiration 2010;79:128-36. [CrossRef]

18. Fine MJ, Auble TE, Yealy DM, Hanusa BH, Weissfeld LA, Singer $\mathrm{DE}$, et al. A prediction rule to identify low-risk patients with community-acquired pneumonia. N Engl J Med 1997;336:24350. [CrossRef]

19. Kaplan V, Angus DC, Griffin MF, Clermont G, Scott Watson R, Linde-Zwirble WT. Hospitalized community-acquired pneumonia in the elderly: age- and sex-related patterns of care and outcome in the United States. Am J Respir Crit Care Med 2002;165:766-72. [CrossRef]

20. Arnold FW, Wiemken TL, Peyrani P, Mirsaeidi M, Ramirez JA; Community Acquired Pneumonia Organization (CAPO) Study Group. Outcomes in females hospitalised with communityacquired pneumonia are worse than in males. Eur Respir J 2013;41:1135-40. [CrossRef] 